\title{
Predictive Control with Current-Based Maximum Power Point-Tracking for On-Grid Photovoltaic Applications
}

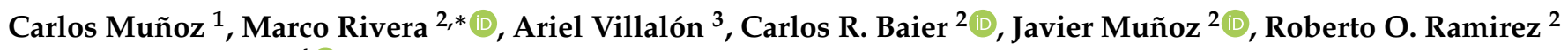 \\ and Patrick Wheeler ${ }^{4}$ (i) \\ 1 Energy Conversion Master Program, Faculty of Engineering, University of Talca, Curicó 3344158, Chile; \\ carlosmunoz@utalca.cl \\ 2 Department of Electrical Engineering, Faculty of Engineering, University of Talca, Curicó 3344158, Chile; \\ cbaier@utalca.cl (C.R.B.); jamunoz@utalca.cl (J.M.); roramirez@utalca.cl (R.O.R.) \\ 3 Engineering Systems Doctoral Program, Faculty of Engineering, University of Talca, Curicó 3344158, Chile; \\ avillalon@utalca.cl \\ 4 Faculty of Engineering, University of Nottingham, Nottingham NG7 2RD, UK; \\ pat.wheeler@nottingham.ac.uk \\ * Correspondence: marcoriv@utalca.cl
}

Citation: Muñoz, C.; Rivera, M.;

Villalón, A.; Baier, C.; Muñoz, J.;

Ramirez, R.O.; Wheeler, P. Predictive

Control with Current-Based

Maximum Power Point-Tracking for On-Grid Photovoltaic Applications.

Sustainability 2021, 13, 3037.

https://doi.org/10.3390/su13063037

Academic Editor: Francesco Tariello

Received: 26 January 2021

Accepted: 5 March 2021

Published: 10 March 2021

Publisher's Note: MDPI stays neutral with regard to jurisdictional claims in published maps and institutional affiliations.

Copyright: (c) 2021 by the authors. Licensee MDPI, Basel, Switzerland. This article is an open access article distributed under the terms and conditions of the Creative Commons Attribution (CC BY) license (https:// creativecommons.org/licenses/by/ $4.0 /)$.

\begin{abstract}
The high increase of renewable energy sources and the increment of distributed generation in the electrical grid has made them complex and of variable parameters, causing potential stability problems to the PI controllers. In this document, a control strategy for power injection to the electrical system from photovoltaic plants through a voltage source inverter two-level-type (VSI-2L) converter is proposed. The algorithm combines a current-based maximum power point-tracking (CurrentBased MPPT) with model predictive control (MPC) strategy, allowing avoidance of the use of PI controllers and lowering of the dependence of high-capacitive value condensers. The sections of this paper describe the parts of the system, control algorithms, and simulated and experimental results that allow observation of the behavior of the proposed strategy.
\end{abstract}

Keywords: photovoltaic; predictive control; current-based MPPT

\section{Introduction}

The current dependence on electrical equipment needed for daily tasks, mobile devices and electromobility has generated a global increase in energy demand [1,2]. As electric energy requirements grow, a change to more environmentally friendly methods has to be made in order to help decrease global greenhouse gases emissions [3].

Electric power systems have used power from renewable sources for some time, mainly from solar and wind energy plants which use of power converters, which obtain the maximum benefit independent of the environmental conditions [4].

Renewable energy sources are often away from the centers of energy demand, therefore the paradigm of unidirectional power systems is changing. Distributed generation is converting power systems into bidirectional-power-flow systems, making them more complex to control and protect [5]. Due to the chance of isolated operation, the concept of microgrids, using the big spread and development of power-electronics-interfaced distributed generation, can be applied [6]. Distributed generation leads to intermittently produced energy by the electrical power systems [7], causing the system parameters to be affected and generates possible divergences in the converter's control loops. Commonly, these power converters use PI-based control schemes, which show good performance when the system works near the nominal operating point [8].

In the literature it is possible to find that solar arrays typically use cascaded doublestage power converters, in which the solar array is connected to the first DC/DC stage in charge of making the solar array function in the maximum power point (MPP), and in 
the second stage, a DC/AC converter in charge of performing a correct power injection to the electrical grid $[9,10]$. The problem about DC/DC stage is that it introduces higher switching losses due to the higher number of semiconductors. It is possible to find singlestage converters for solar applications as well, which present a higher global robustness and efficiency in comparison to the single staged ones [11,12].

In the literature it is possible to find that solar arrays typically use cascaded doublestage power converters, in which the solar array is connected to the first DC/DC stage in charge of making the solar array function in the maximum power point (MPP), and in the second stage, a DC/AC converter in charge of performing a correct power injection to the electricity grid $[9,10]$. The problem about DC/DC stage is that it introduces higher switching losses due to the higher number of semiconductors. It is possible to find singlestage converters for solar applications as well, which present a higher global robustness and efficiency in comparison to the single staged ones [11,12].

Numerous power converter topologies have a capacitor as a voltage stabilizer in the DC link that is responsible for keeping the voltage as stable as possible. This capacitor is under constant stress due to the frequency components that are reflected from the AC side to the DC side, which decrease the capacitor's lifespan [13,14]. Most strategies for solar applications control the voltage on this capacitor, minimizing ripple with larger capacitors, thus increases the cost [15].

Lately, MPC has become better known and consequently, more developed [16]. This control scheme requires the mathematical model of the plant with which it is capable of taking control action to track references. It is well suited for power converters due to the discrete nature of power switches, making it easy to evaluate all the options available in a mathematical model. It is important not to forget that this control allows control of non-linear systems, being able to adapt itself to variations in the parameters, and its dynamics are much faster when compared to classic strategies [17,18].

Model predictive control for solar photovoltaic systems has been applied to solar pumping systems where cascade control has often been used. The internal current-control loop can be replaced with predictive control [19-21]. The latter has resulted in an improved dynamic response and more robustness in the control. Also, this has allowed the use of different power converters topologies, including those where a balance of capacitor voltages is required $[22,23]$.

The perturbation and observation $(\mathrm{P} \& \mathrm{O})$ strategy is the most found in the literature. It is based on producing disturbances in a variable that operates as an actuator and subsequently evaluating how the power of the system evolves. It is possible to find different variations of the $\mathrm{P} \& \mathrm{O}$ strategy, where the variable to be modified will mainly depend on the energy storage element available in the power converter used [24]. For voltage source-type inverters, voltage disturbances are typically created, because the DCside capacitor operates as a voltage stabilizer $[25,26]$.

The implementation for $\mathrm{P} \& \mathrm{O}$ maximum power point-tracking (MPPT) strategies that are based on current or voltage, relies primarily on the parameters associated with the power converter's storage element which is being controlled. In this way, current-based MPPT strategies can be implemented for current control at the AC-side inductor for voltage topologies, and thus, reducing the dependence on the DC side's capacitors [27].

Motivated by the characteristics of the aforementioned strategies, this paper proposes the usage of power injection to the electrical grid from a solar system using a predictive current-control scheme, with a current-based strategy for MPPT and feedback from the solar array current to obtain the reference for the control. This MPPT algorithm provokes disturbances in the reference current to be injected into the grid. Afterwards, it analyzes whether the power delivered by the solar array increases or decreases with this new condition, allowing a new decision to be made regarding the reference current in the next step. This allows the current to be injected into the system with a low harmonic content, independent of the system's variables, and also reduces the need for large and costly capacitor banks as well. 
The contribution of this work is the development of a control strategy that allows operating solar arrays with a reduced number of control stages and has few parameters for its design, the novelty being the development of an MPPT strategy based on current for a voltage source converter that is able to directly communicate with the current control on the AC side. The proposed strategy is capable of operating in electrical networks, setting PI control completely aside, allowing continuation of operation before variations in their electrical parameters without damaging the harmonic content of the injected current, as well as enabling the size reduction of the capacitor used in voltage source-type converters.

At the beginning of the document, a description of the system and the used controls is provided alongside design considerations, after this, the results obtained through simulation are presented considering a non-ideal electrical system with resistive and inductive parameters. For the simulation, three cases were contemplated: simulation with the proposed control, simulation with the proposed control reducing the DC link condenser, and a simulation with cascaded PI controllers for a further comparison. A new simulation considering disturbances in the voltage of the grid was run. Finally, the experimental results obtained for the proposed control, discussion and conclusions are shown.

\section{System Description}

The proposed control strategy is shown in Figure 1, which displays a solar array coupled to a single-stage converter, a resistive inductive $(R L)$ filter, an isolation transformer and a representation of the electrical grid [28].

This strategy is a model predictive current-control technique, In which the amplitude of the reference is taken directly from the MPPT algorithm [27,29]. Each part of the system and the control loops used are described with the aim of having a clear understanding of the control scheme.

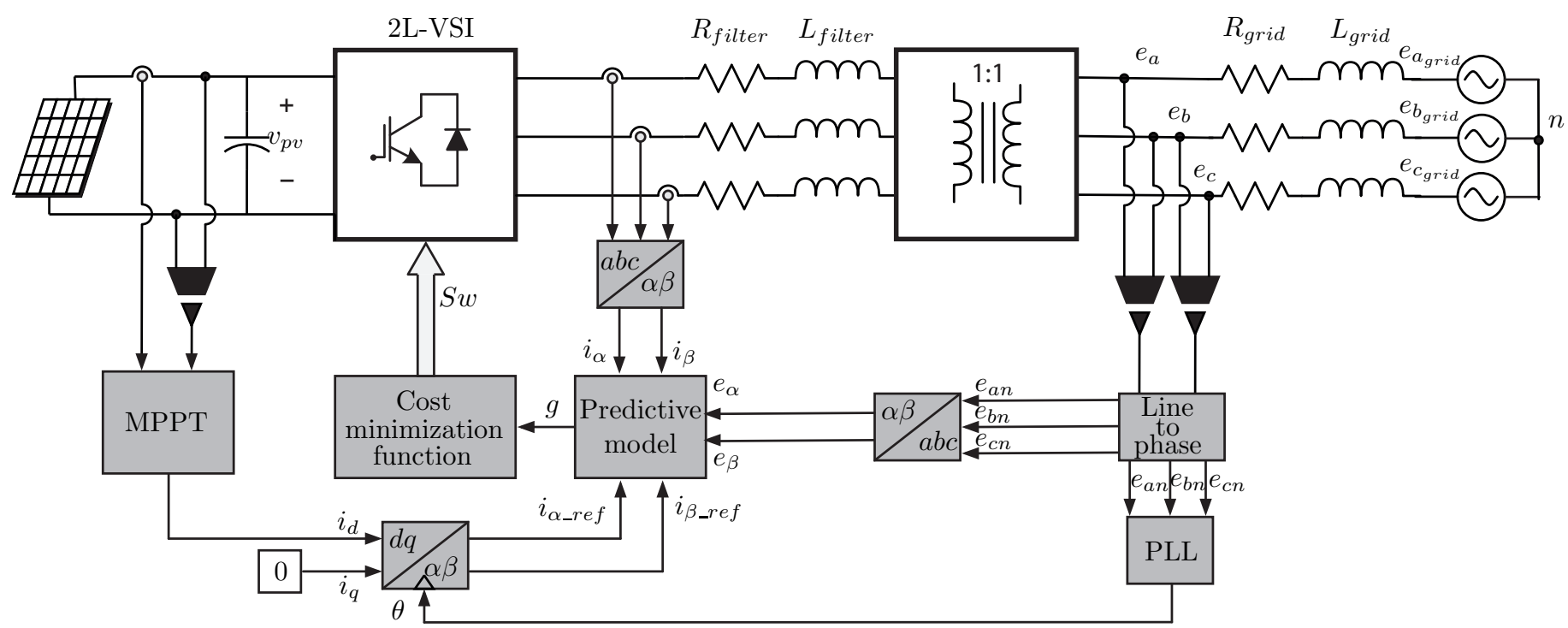

Figure 1. Global control scheme.

\subsection{Photovoltaic Array}

The photovoltaic array consists of a set of solar panels that can be modeled considering the non-linear behavior that is due to temperature and irradiance conditions [30]. Thus, a power converter is needed to allow the maximum power from the solar array to deal with disturbances in the electrical variables.

In order for the suggested scheme to work, a solar panels array must be connected in parallel to a capacitor that is responsible for keeping the voltage on the DC side stable in case of disturbances. The capacitor voltage depends on the one hand, on the environmental conditions, and on the other, on the current required at the AC side [31]. 
It should be mentioned that panels that are series-connected should be considered, since, for single-stage systems, it is necessary to have a voltage in the DC link higher than the rectified grid voltage, to allow a power injection into the electrical system [32].

\subsection{Power Converter}

For the purpose of extracting maximum power from the solar array, a two-level voltage source inverter (2L-VSI) is used. This converter was selected due to its simplicity of construction and development. The power converter is represented in Figure 2. This is composed of three legs, each with two power switches which operate in a complementary way with each other in order to avoid short circuits or loss of control over the load. The valid states of the converter are presented in Table 1.

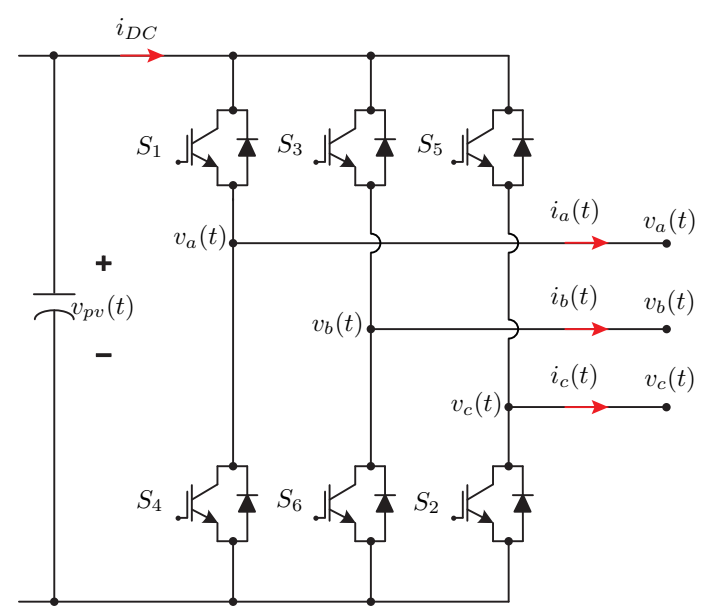

Figure 2. Two-level voltage source inverter (2L-VSI).

Table 1. 2L-VSI valid states.

\begin{tabular}{ccccccc}
\hline States & $S_{1}$ & $S_{2}$ & $S_{3}$ & $S_{4}$ & $S_{5}$ & $S_{6}$ \\
\hline 1 & 1 & 1 & 0 & 0 & 0 & 1 \\
2 & 1 & 1 & 1 & 0 & 0 & 0 \\
3 & 0 & 1 & 1 & 1 & 0 & 0 \\
4 & 0 & 0 & 1 & 1 & 1 & 0 \\
5 & 0 & 0 & 0 & 1 & 1 & 1 \\
6 & 1 & 0 & 0 & 0 & 1 & 1 \\
7 & 1 & 0 & 1 & 0 & 1 & 0 \\
8 & 0 & 1 & 0 & 1 & 0 & 1 \\
\hline
\end{tabular}

\subsection{Proposed MPPT Strategy Current-Based}

Considering that the power behavior in the photovoltaic system varies depending on environmental conditions, and in most cases it is expected that photovoltaic generating plants deliver the maximum available power, it is necessary to use a maximum power pointtracking algorithm (MPPT) [33] that allows operating the solar arrays at the maximum power point (MPP).

To implement the proposed MPPT algorithm, a sample of the voltage $\left(v_{p v}(t)\right)$ and the current $\left(i_{p v}(t)\right)$ of the solar array in the present state must be taken every $T_{S M P P T}$ period. With these measurements, the operating power of the panels $\left(P_{p v}(t)\right)$ is calculated. Subsequently, the variations of current $\left(\Delta i_{p v}(t)\right)$ and power $\left(\Delta P_{p v}(t)\right)$ between the current and previous state are obtained. 
With the slopes of power $\left(\Delta P_{p v}(t)\right)$ and current $\left(\Delta i_{p v}(t)\right)$, the algorithm determines if the next iteration should increase $\left(i_{r e f}=\left(i_{r e f}+\Delta i\right)-i_{p v}\right)$ or decrease $\left(i_{r e f}=\left(i_{r e f}-\Delta i\right)-i_{p v}\right)$ the reference current in the developed predictive control strategy. Finally, the current measurements are stored in memory, to be used in the next step as the previous values. The above is described step by step in Table 2.

A current-based $\mathrm{P} \& \mathrm{O}$ algorithm makes disturbances in the AC-side current and analyzes the behavior of the variables on the DC side, thus, allowing the removal of the capacitance value dependence. As a result, there is no need to consider a voltage control loop for the capacitor, prompting a lower total harmonic distortion (THD) in the injected current than in the values that are obtained using a PI-based control strategies [34].

This strategy is similar to a regular voltage-based $\mathrm{P} \& \mathrm{O}$ algorithm, but the difference is that its output corresponds to the current reference. Please note that the proposed strategy considers the subtraction of the current $i_{p v}$ in the output. This works as a feed-forward loop to the algorithm, since the current delivered by the solar panel is proportional to the solar irradiance.

Table 2. Current-based MPPT strategy steps.

\begin{tabular}{|c|c|}
\hline Step & Action \\
\hline Step 1 & Measure $v_{p v}$ and $i_{p v}$ \\
\hline Step 2 & Calculate $P_{p v}$ with $v_{p v}$ and $i_{p v}$ \\
\hline Step 3 & Calculate $\Delta P_{p v}$ with $P_{p v}(t)$ and $P_{p v}\left(t-T_{S ~ M P P T}\right)$ \\
\hline Step 4 & Calculate $\Delta i_{p v}$ with $i_{p v}(t)$ and $i_{p v}\left(t-T_{S} M P P T\right)$ \\
\hline Step 5 & If $\left(\Delta P_{p v}=0\right)\{$ go to Step 1$\}$ else $\{$ go to Step 6$\}$ \\
\hline Step 6 & If $\left(\Delta P_{p v}<0\right.$ and $\left.\Delta i_{p v}<0\right)\{$ go to Step 10$\}$ else $\{$ go to Step 7$\}$ \\
\hline Step 7 & If $\left(\Delta P_{p v}<0\right.$ and $\left.\Delta i_{p v}>0\right)\{$ go to Step 1$\}$ else $\{$ go to Step 8$\}$ \\
\hline Step 8 & If $\left(\Delta P_{p v}>0\right.$ and $\left.\Delta i_{p v}<0\right)\{$ go to Step 11$\}$ else $\{$ go to Step 9$\}$ \\
\hline Step 9 & If $\left(\Delta P_{p v}>0\right.$ and $\left.\Delta i_{p v}>0\right)\{$ go to Step 10$\}$ \\
\hline Step 10 & $i_{r e f}=\left(i_{r e f}+\Delta i\right)-i_{p v}$ and go to Step 12 \\
\hline Step 11 & $i_{r e f}=\left(i_{r e f}-\Delta i\right)-i_{p v}$ and go to Step 12 \\
\hline Step 12 & Return to Step 1 \\
\hline
\end{tabular}

\subsection{Reference Plane Transform}

To implement the proposed MPPT strategy, it is necessary to use spatial transforms, which allow to take the output of the current-based P\&O MPPT directly. The latter allows communication between the MPPT strategy and the AC-side current control.

Since the algorithm of the predictive control works in the $\alpha \beta$ plane with the purpose of reducing the number of the control equations, transforms from the plane $d q$ to $\alpha \beta$ are used for the DC side in function to communicate the DC whit the AC side, and finally transforms from the plane $a b c$ to $\alpha \beta$, for the current and voltage grid measurements.

Lastly, and to make unity power factor injection possible, a grid voltage phase-locked loop (PLL) is used [35], this allows the synchronization of said transforms to the electrical system voltage. Please note that the algorithm also permits reactive power injection if needed.

\subsection{Phase-Locked Loop Algorithm}

The control algorithm shown in Figure 3 is used to obtain the $\theta$ angle. In this diagram, a transform from the plane $a b c$ to $d q$ that takes the voltage signal $e^{q}$ is considered. This signal is passed through a discrete filter $\left(\right.$ Filter $\left._{P L L}(z)\right)$ that allows a noise reduction of the measurement. A discrete PI controller $\left(P I_{P L L}(z)\right)$ is used to find the angular velocity that allows obtaining zero error in steady state (this point being synchronized with the grid) and an integral in the $z$ plane that takes the angular velocity and returns the required angle $\theta$. The closed loop shown is fed back with a constant $2 \pi 50$ that accelerates the convergence, given that the frequency of the grid is known. The transfer functions $\operatorname{Filter}_{P L L}(z), P I_{P L L}(z)$ and integral in the $z$ plane are given by Equations (1)-(3), respectively. 


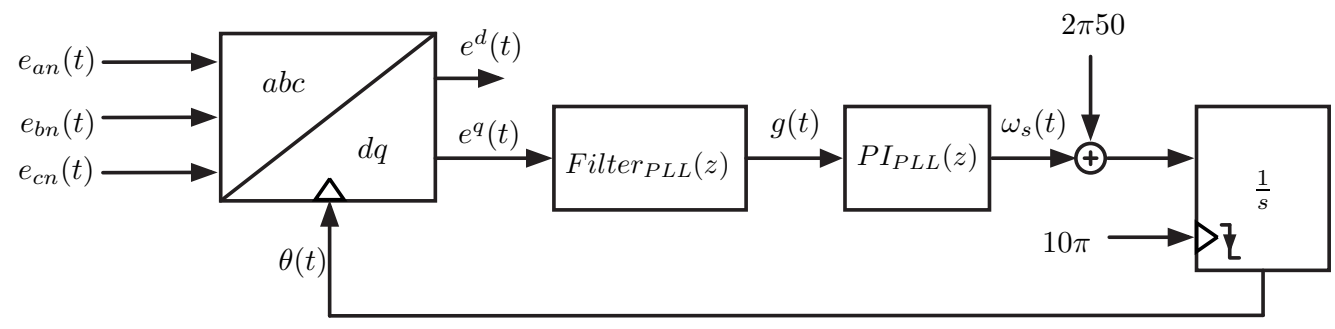

Figure 3. PLL control scheme.

$$
\begin{gathered}
\text { Filter } P L L(z)=\frac{\alpha z}{z+(\alpha-1)} \\
P I_{P L L}(z)=\frac{k_{1} z-k_{2}}{z-1} \\
\text { integral }(z)=\frac{T_{s_{P L L}}(z+1)}{2(z-1)}
\end{gathered}
$$

\subsection{Current Control for Power Injection to the Grid}

Considering that the connection points of solar plants can have large variations in their parameters due to the grid robustness, distributed generation and integration of renewable energy, it is proposed to use predictive current control for the current injection to the electrical grid, which allows to improve the response dynamics and operate with non-linear systems [36]. Note in Figure 1 that, in this study, the current predictive control reference is addressed from the MPPT strategy, going through the transform $d q$ to $\alpha \beta$, allowing communication of the MPPT algorithm with the predictive control.

The implementation of model predictive control (MPC) requires a mathematical model of the plant to be controlled, in which all the possible conditions of the actuator can be evaluated. This makes MPC ideal for power converters, because to its discrete nature $[37,38]$.

Regarding the proposed strategy, all the 2L-VSI states are shown in Table 1 and must be evaluated to determine the optimal switching vector that generates the minimum error in the output current with respect to the reference. Considering that the connection point of the converter (including the filter and transformer) corresponds to nodes $e_{a}, e_{b}$ and $e_{c}$, shown in Figure 1, an KVL (Kirchhoff's Voltage Law) is performed between the converter and the aforementioned nodes obtaining Equation (4). Selecting this point to apply the KVL allows not to depend on the grid parameters for the functioning of the control.

$$
v^{a b c}(t)=i^{a b c}(t) R_{f i l t e r}+L_{f i l t e r} \frac{d v^{a b c}(t)}{d t}+e^{a b c}(t)
$$

Predictive control has a limitation in the computational capacity required to solve the mathematics of the models. To deal with this, the Clarke transform is used to simplify from a three-phase $a b c$ plane to only two variables in $\alpha \beta$ plane. Considering this, Equation (5) is obtained.

$$
v^{\alpha \beta}(t)=i^{\alpha \beta}(t) R_{\text {filter }}+L_{\text {filter }} \frac{d i^{\alpha \beta}(t)}{d t}+e^{\alpha \beta}(t)
$$


Using the forward Euler approach (6) and replacing in (5), the equation for the predictive model (7) can be obtained in discrete time.

$$
\begin{gathered}
\frac{d i(t)}{d t}=\frac{i_{k+1}-i_{k}}{T_{s}} \\
i_{k+1}^{\alpha \beta}=\left(1-\frac{T_{s} R_{\text {filter }}}{L_{\text {filter }}}\right) i_{k+1}^{\alpha \beta}+\frac{T_{s}}{L_{\text {filter }}}\left(v_{k}^{\alpha \beta}-e_{k}^{\alpha \beta}\right)
\end{gathered}
$$

To implement this control strategy, the finite switching states must be considered. Each converter admissible state generates a load voltage vector (shown in Equation (8)) that is transformed to the $\alpha \beta$ plane using the Clarke transform, obtaining vectors $v_{\alpha k}$ and $v_{\beta k}$. These vectors are evaluated in Equation (7), allowing current prediction to be obtained for all valid switching states for the $(k+1)$ sampling time [39].

$$
v^{a b c}=\frac{1}{3}\left[\begin{array}{ccc}
2 & -1 & -1 \\
-1 & 2 & -1 \\
-1 & -1 & 2
\end{array}\right]\left[\begin{array}{l}
S_{1} \\
S_{3} \\
S_{5}
\end{array}\right] v_{p v}
$$

Thus, considering the eight switching states on the $\alpha \beta$ plane on Equation (7), eight possible current predictions can be obtained for both alpha and beta plane $\left(i_{k+1}^{\alpha \beta}\right)$. Please note that although the switching states are binary values, the currents correspond to real values. With the purpose of minimizing the errors between the output and the current reference, the square errors for the instant currents in alpha and beta are obtained according to (9), which ensures stability and control convergence [40]. The foregoing allows the generation of the $g$ vector of dimension equal to the number of combinations of the converter, from which the position with less value that allows the determination of the optimal switching combination to apply on the next state is selected.

$$
g=\left(i_{r e f}^{\alpha}-i_{k+1}^{\alpha}\right)^{2}+\left(i_{r e f}^{\beta}-i_{k+1}^{\beta}\right)^{2}
$$

It often stated that predictive control must consider compensation for delays [41] because once a state has been applied, its response can only be observed one sampling cycle later. This is because there is an associated delay in the analog to digital converter (ADC) in the microcontroller. The delay compensation performs a prediction for the state $k+2$ according to Equation (10), where all the switching states are evaluated and the current $i(k+1)$ previously obtained considering the newly applied switching state generated by the previous prediction of $i(k+2)$, which corresponds to a horizon one considering delay compensation [42]. Figure 4 shows the flowchart of the predictive current control including the delay compensation.

$$
i_{k+2}=\left(1-\frac{T_{s} R_{\text {filter }}}{L_{\text {filter }}}\right) i_{k+1}+\frac{T_{s}}{L_{\text {filter }}}\left(v_{k}-e_{k}\right)
$$




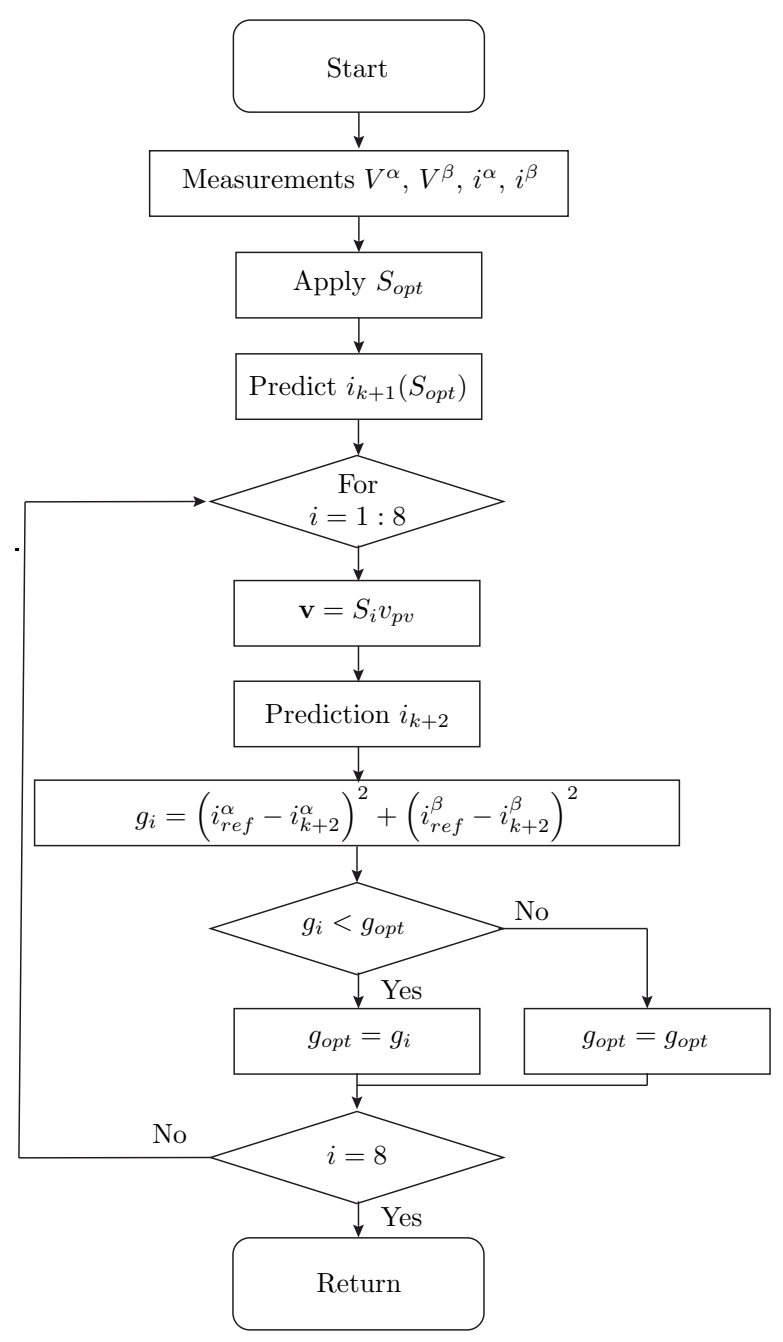

Figure 4. Classic predictive control flowchart considering delay compensation.

\section{Simulations}

Intending to validate the proposed strategy shown in Figure 2, simulations were carried out using MATLAB/Simulink. A comparison is made between the proposed system and the cascade control strategy using sinusoidal pulse-width modulation (SPWM), to analyze and contrast the performance of both algorithms. This control strategy has been described previously and the design criteria is shown in this section in order to clearly demonstrate cascade control.

\subsection{Cascade Controller Design}

The majority of single-stage power converter topologies use cascade, PI for control, the internal loop for current control and the external loop for voltage control [43]. For solar arrays, the voltage loop controls the operating voltage of the solar array based on making it work in its MPP, delivering a reference current to the output. The current loop modifies the modulation of the converter, to track the current reference.

To provide a contrast with the proposed strategy, a simulation is shown in Figure 5, in which the reference voltage is obtained from P\&O MPPT strategy [24] with a $1 \mathrm{~ms}$ step for the MPPT and voltage reference changes $\Delta v$ of $0.1 \mathrm{~V}$. The current reference $i^{q}(s)$ is considered to be 0 (no injected reactive power). The constant $G_{a c}$ corresponds to the converter gain, equal to 0.5 .

For the design of the controllers, the transfer functions (11) and (12) were used for the AC side and (13) as the transfer function of the capacitor on the DC side. 


$$
\begin{gathered}
H^{d}(s)=\frac{\frac{G_{a c} v_{p v}}{L_{\text {filter }}}}{s+\frac{R_{f i l t e r}}{L_{\text {filter }}}} \\
H^{q}(s)=\frac{\frac{G_{a c} v_{p v}}{L_{\text {filter }}}}{s+\frac{R_{f i l t e r}}{L_{\text {filter }}}} \\
H_{d c}(s)=\frac{2 e^{d}}{C s}
\end{gathered}
$$

In the design of the $P I_{\text {current }}(s)$ controllers, a bandwidth of $1000 \frac{\mathrm{rad}}{\mathrm{s}}$ and a damping coefficient of 0.707 were considered for closed-loop design criteria, obtaining the parameters of the $P I_{\text {current }}(s)$ as shown in (14).

$$
P I_{\text {current }}(s)=\frac{k_{i \_i}}{s}+k_{p_{-} i}=\frac{225.1494}{s}+0.3006
$$

The voltage controller was designed with a bandwidth 20 times slower than the current one (50 $\frac{\mathrm{rad}}{\mathrm{s}}$ ) and with a damping of 0.707 , obtaining the constants shown in (15).

$$
P I_{\text {voltage }}(s)=\frac{k_{i_{-} v}}{s}+k_{p_{-} v}=\frac{0.0258}{s}+0.00074142
$$

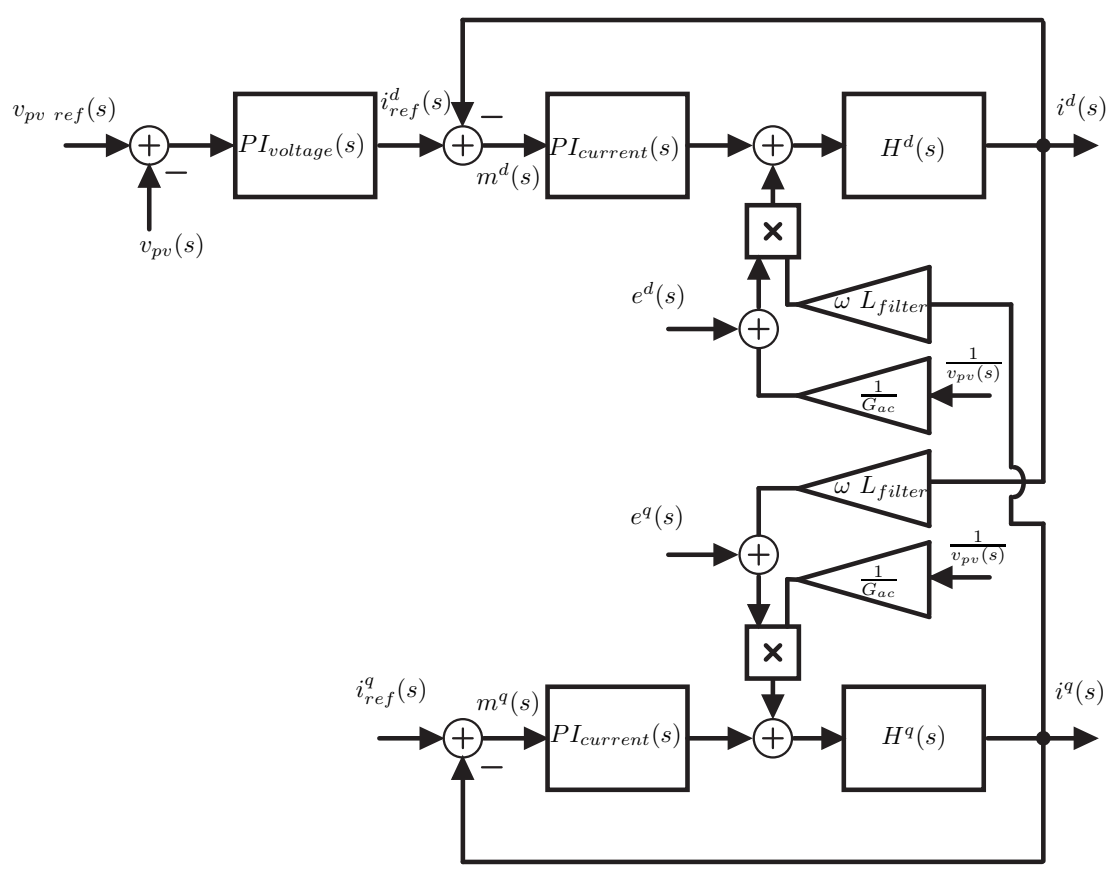

Figure 5. Diagram cascade PI control.

\subsection{Simulation Results}

In this section, the results obtained by simulation using MATLAB/Simulink software are presented, considering the parameters in Tables 3-7 and with three different conditions: 
Table 3. PV modules parameters simulation.

\begin{tabular}{ll}
\hline Parameter & Value \\
\hline Maximum power per module & $49.59 \mathrm{~W}$ \\
Cells per module & 12 \\
Open-circuit voltage $\left(V_{o v}\right)$ per module & $22.4 \mathrm{~V}$ \\
Short-circuit current $\left(I_{s c}\right)$ per module & $3 \mathrm{~A}$ \\
Maximum power point voltage $\left(V_{m p p}\right)$ per module & $17.4 \mathrm{~V}$ \\
Maximum power point current $\left(I_{m p p}\right)$ per module & $2.85 \mathrm{~A}$ \\
Parallel modules & 1 \\
Series modules & 5 \\
$\mathrm{~T}^{\circ}$ coefficient $V_{o c}$ & -0.36099 \\
$\mathrm{~T}^{\circ}$ coefficient $I_{s c}$ & 0.102 \\
\hline
\end{tabular}

Table 4. AC side parameters simulation.

\begin{tabular}{ll}
\hline Parameter & Value \\
\hline$R_{\text {filter }}$ & $1 \Omega$ \\
$L_{\text {filter }}$ & $10 \mathrm{mH}$ \\
$R_{\text {grid }}$ & $1 \Omega$ \\
$L_{\text {grid }}$ & $10 \mathrm{mH}$ \\
$e_{\text {grid }}$ & $20 \mathrm{~V}$ \\
\hline
\end{tabular}

Table 5. DC-side parameters simulation.

\begin{tabular}{ll}
\hline Parameter & Value \\
\hline$C$ & $600 \mu \mathrm{F}$ \\
$C$ (case lower capacitance) & $200 \mu \mathrm{F}$ \\
\hline
\end{tabular}

Table 6. Proposed control parameters simulation.

\begin{tabular}{ll}
\hline Parameter & Value \\
\hline$T_{S}$ & $20 \mu \mathrm{s}$ \\
$T_{S} M P P T$ & $1 \mathrm{~ms}$ \\
$\Delta i$ & $20 \mathrm{~mA}$ \\
$k_{1}$ & 5 \\
$k_{2}$ & -5 \\
$\alpha$ & 0.001 \\
$T_{S P L L}$ & $20 \mu \mathrm{s}$ \\
\hline
\end{tabular}

Table 7. Cascade control parameters simulation.

\begin{tabular}{ll}
\hline Parameter & Value \\
\hline$k_{p_{-} i}$ & 0.3006 \\
$k_{i_{-} i}$ & 225.1494 \\
$k_{p_{-} v}$ & 0.00074142 \\
$k_{i_{-} v}$ & 0.0258 \\
$G_{a c}$ & 0.5 \\
$\Delta v$ & $0.1 \mathrm{~V}$ \\
$T_{S M P P T}$ & $1 \mathrm{~ms}$ \\
$T_{s}$ & $100 \mu \mathrm{s}$ \\
\hline
\end{tabular}


- $\quad$ Proposed control strategy.

- Control strategy proposed with a capacitor with a lower capacitive value.

- Cascade control strategy.

To show that the proposed strategy was dependent on the parameters of the electrical grid filter, simulation results have been obtained considering a decrease in the value of the capacitor bank. It is important to mention that the $\Delta i$ parameter must not be an overly high number, for it would introduce considerable subharmonics into the current injected to the grid, whereby a small value that could be perceived in the current sensor used in the implementation is considered. The $\triangle T_{S}$ MPPT parameter allows the acceleration or delaying of the control algorithm. How much it can be accelerated will mainly depend on the inductive parameter of the electric grid.

To observe the response under the three different conditions, disturbances in the environmental parameters are considered. At the beginning of the simulation there is a solar irradiance of $1000\left[\mathrm{~W} / \mathrm{m}^{2}\right]$ and a temperature of $25\left[{ }^{\circ} \mathrm{C}\right]$. At $1.5 \mathrm{~s}$, a stepwise decrease in solar irradiance from 1000 to $800\left[\mathrm{~W} / \mathrm{m}^{2}\right]$ is made. At $2.5 \mathrm{~s}$, the solar irradiance returns to the condition of $1000\left[\mathrm{~W} / \mathrm{m}^{2}\right]$. Then, disturbances are provoked in the solar cell temperature and a stepwise increase from 25 to $45\left[{ }^{\circ} \mathrm{C}\right]$ occurs at $3.5 \mathrm{~s}$. After $4.5 \mathrm{~s}$, the temperature returns to the initial condition. The results are shown in Figures 6 and 7, and a summary of the results is presented in Table 8 . Please note that $T_{0-M P P}$ corresponds to the amount of time the algorithm takes in going from 0 to the MPP.

Table 8. Resumed results.

\begin{tabular}{ccccc}
\hline Simulation & $\boldsymbol{T H D}_{v 51}$ & $\boldsymbol{W T H D}_{\boldsymbol{v}}$ & Mean Error & $\boldsymbol{T}_{\mathbf{0}}$ MPP \\
\hline Proposed strategy & 9.8108 & 0.40175 & $0.061491 \mathrm{~A}$ & $0.41 \mathrm{~s}$ \\
\hline Proposed strategy with less capacitance & 10.4537 & 0.39199 & $0.066414 \mathrm{~A}$ & $0.41 \mathrm{~s}$ \\
\hline PI control & 5.5317 & 0.66788 & $0.096278 \mathrm{~A}$ & $0.26 \mathrm{~s}$ \\
\hline
\end{tabular}

\subsubsection{Simulation Results with Distortion in the Power Grid}

Intending to demonstrate the potential of the proposed strategy, Figures 8 and 9 show the simulations of the system with distortion in the grid voltage. Equations (16)-(18) show the grid voltages considering third, fifth and seventh order harmonics, as well as phase-shift and unbalance in the grid voltages. The idea is to show the good performance of the proposed algorithm in the face of poor electrical network conditions.

$$
\begin{gathered}
e_{\text {agrid }}=20 \sqrt{2}\left(\left(1.2 \sin \left(w t+180^{\circ}\right)\right)+0.05 \sin \left(3\left(w t+180^{\circ}\right)\right)+0.03 \sin \left(5\left(w t+180^{\circ}\right)\right)+0.03 \sin \left(7\left(w t+180^{\circ}\right)\right)\right) \\
e_{\text {bgrid }}=20 \sqrt{2}\left(\left(\frac{1}{\sqrt{(2)}} \sin \left(w t+60^{\circ}\right)\right)+0.05 \sin \left(3\left(w t+60^{\circ}\right)\right)+0.03 \sin \left(5\left(w t+60^{\circ}\right)\right)+0.03 \sin \left(7\left(w t+60^{\circ}\right)\right)\right) \\
\left.e_{\text {cgrid }}=20 \sqrt{2}\left(0.8 \sin \left(w t+305^{\circ}\right)\right)+0.05 \sin \left(3\left(w t+305^{\circ}\right)\right)+0.03 \sin \left(5\left(w t+305^{\circ}\right)\right)+0.03 \sin \left(7\left(w t+305^{\circ}\right)\right)\right)
\end{gathered}
$$

Figures 8 and 9 shown simulation results even under disturbances in the environmental parameters. Results expose that the proposed strategy may control considering voltage grid distortion.

Figures 8 and 9 show that the proposed strategy is able to control the system considering variations of environmental parameters and even under electrical grid distortions. 


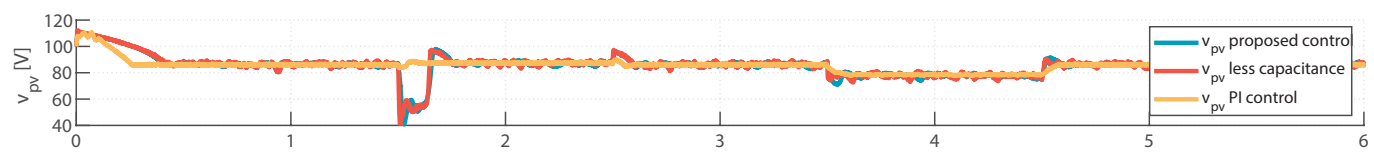

(a)

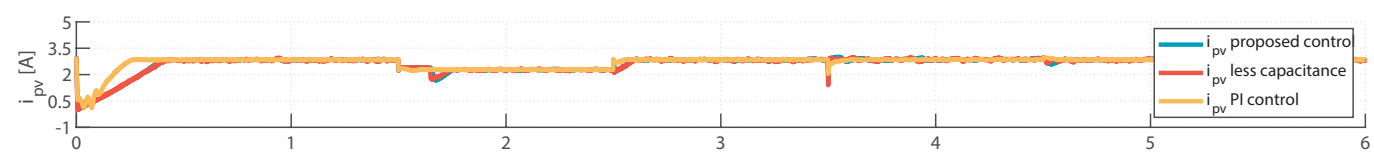

(b)

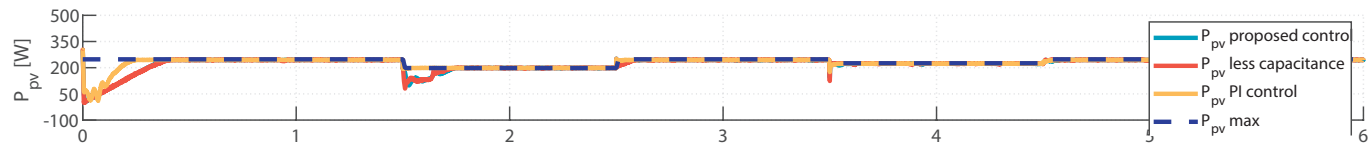

(c)

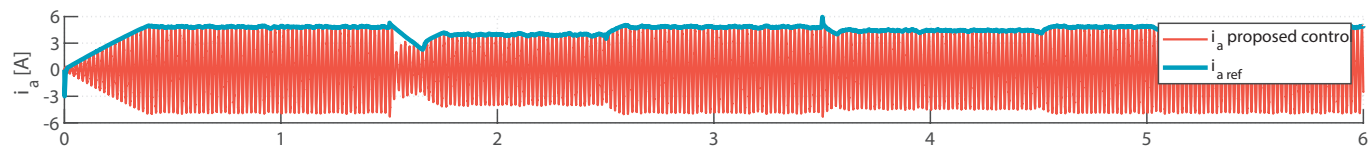

(d)

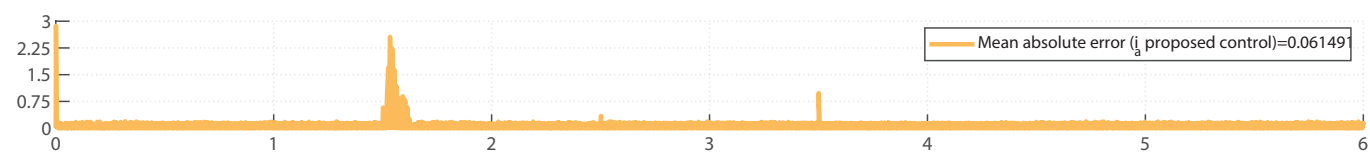

(e)

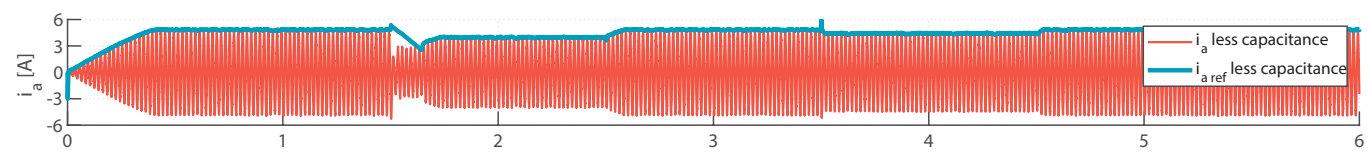

(f)

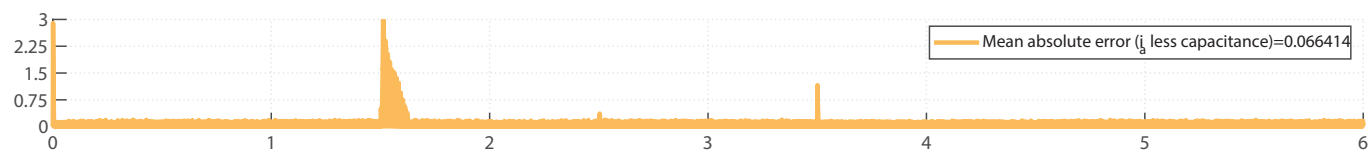

(g)

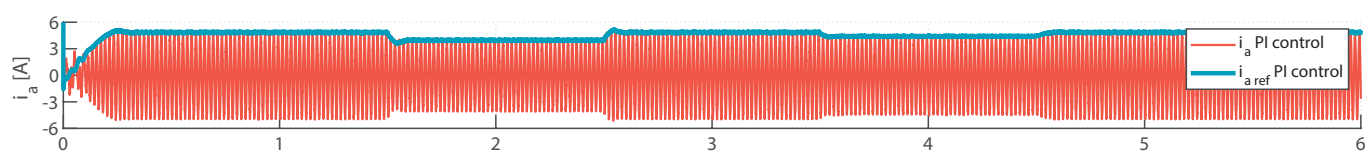

(h)

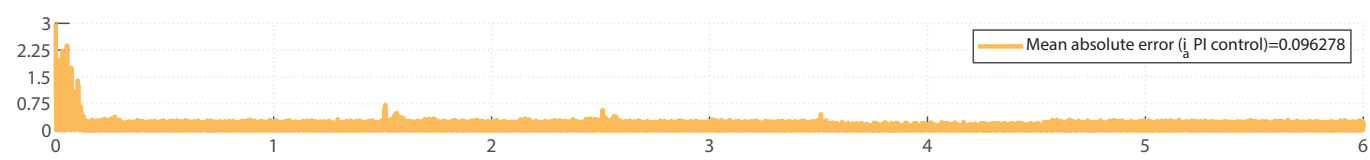

(i)

Figure 6. Simulation results: (a) DC link voltage for three disturbance simulations, (b) solar panel current for three disturbance simulations, (c) operating power of the solar array under disturbances, (d) current $i_{a}$ and its reference for the proposed control under disturbances, (e) error between the output current and reference in figure (e,f) current $i_{a}$ and its reference using lower capacitance under disturbances, $(\mathbf{g})$ error between the output current and reference of the figure $(\mathbf{f}, \mathbf{h})$ current $i_{a}$ and its reference for the PI controller under disturbances, (i) error between the output current and reference of figure (h). 


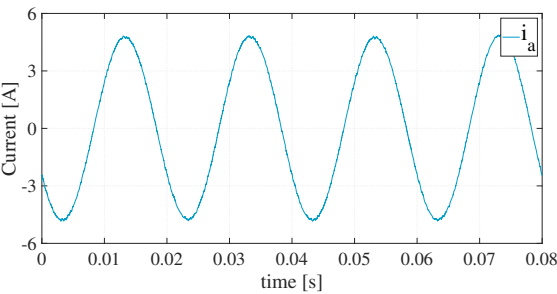

(a)

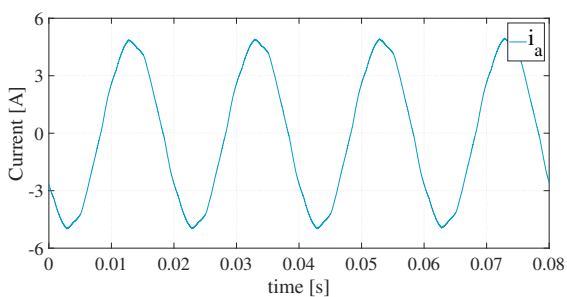

(c)

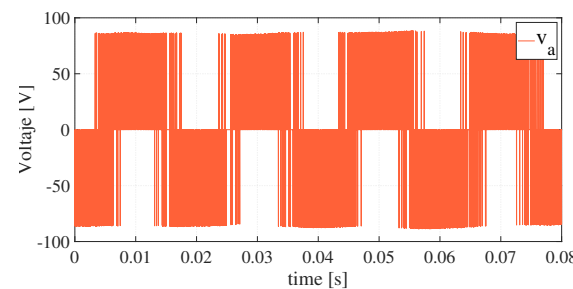

(e)

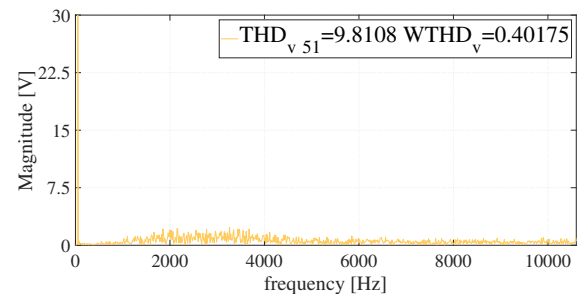

(g)

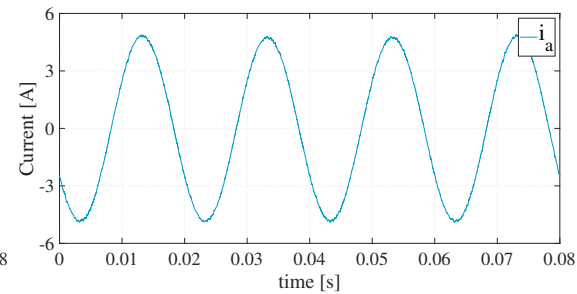

(b)

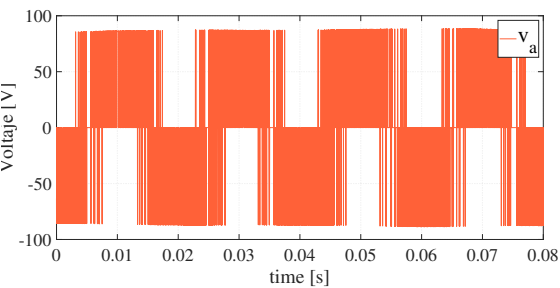

(d)

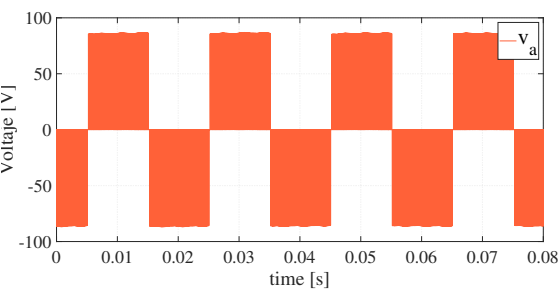

(f)

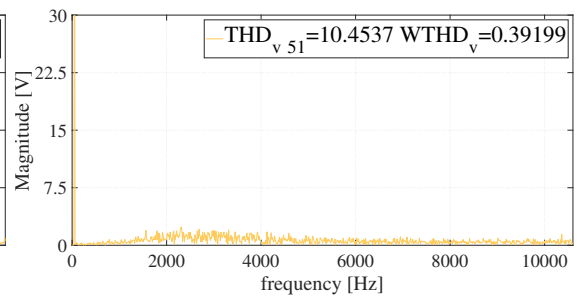

(h)

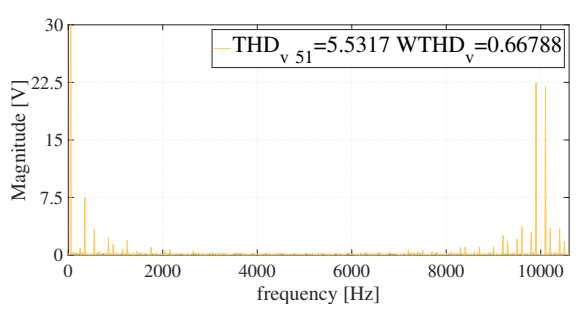

(i)

Figure 7. Simulation results: (a) steady state current $i_{a}$ for the proposed strategy, (b) steady state current $i_{a}$ for the simulation with lower capacitance, (c) steady state current $i_{a}$ for the PI control, (d) steady state voltage $v_{a}$ for the proposed strategy, (e) steady state voltage $v_{a}$ for the simulation with lower capacitance, (f) voltage $v_{a}$ steady state for PI control, (g) voltage spectral analysis of (d) and calculation of THD and WTHD, (h) voltage spectral analysis of (e) and calculation of THD and WTHD, (i) spectral analysis of the voltage of (f) and calculation of THD and WTHD. 


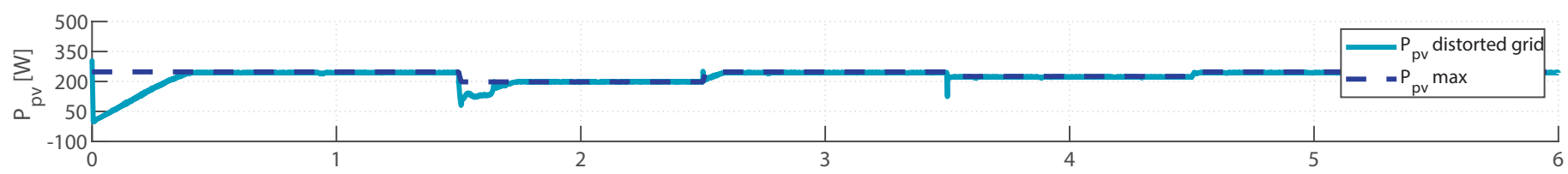

Figure 8. Simulation results: operating power of the solar array under disturbances considering a distorted grid voltage.

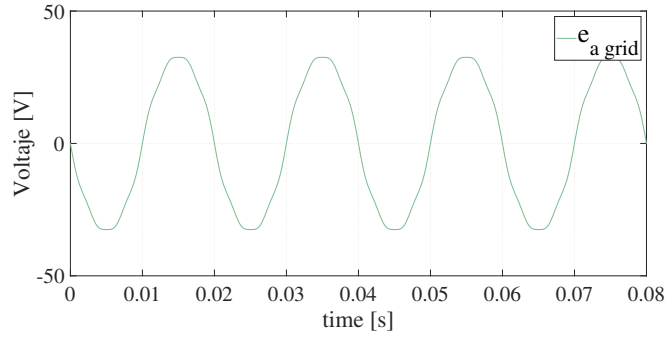

(a)

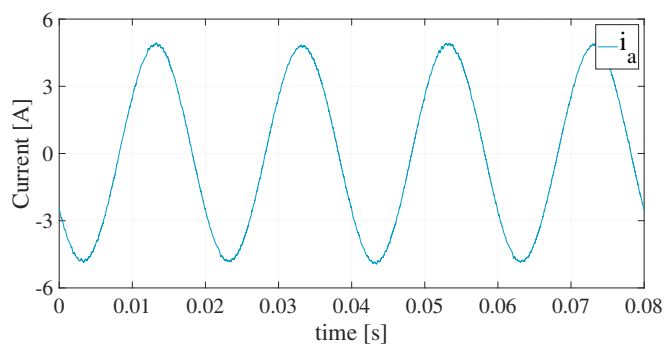

(c)

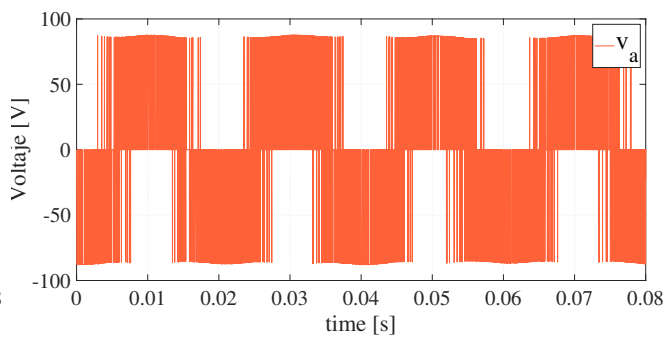

(b)

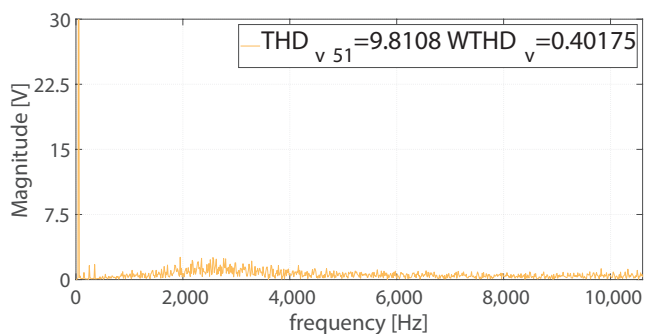

(d)

Figure 9. Simulation results: (a) voltage $e_{a}$ grid for distorted grid (b) steady state voltage $v_{a}$ considering distorted grid, (c) steady state current $i_{a}$ considering distorted grid, (d) voltage spectral analysis of (b) and calculation of THD and WTHD.

\subsubsection{Experimental Results}

Experimental tests are conducted using solar panels connected in series (model ED50$6 \mathrm{M})$ to validate the simulation results. To emulate sudden disturbances in solar conditions, a bypass is performed for one of the panels using a two-position relay, controlled by a digital signal. The only difference compared to the simulation parameters of the proposed strategy is that a $T_{S}$ MPPT of $20[\mathrm{~ms}]$ is used.

In Figure 10 the setup used for this work is shown and the results obtained are presented in Figure 11. To clearly illustrate the behavior of the experimental results and proper operation of the algorithm, the results are considered during the MPPT algorithm start, disturbance in the number of solar panels connected in series to emulate decrease in solar irradiance and loss of available power (a bypass is made to one of the solar panels of the series-connected array) and steady state signals to see the quality of the signals.

In Figure $11 a, d, g, j$ the signals are shown from the start of the control to the establishment of the MPP, considering 6 solar panels connected in series. Figure 11b,e,h,k show the behavior of the system during the disconnection of one of the solar panels (at approximately $0.5 \mathrm{~s}$ ), and then during the connection (approximately after $2 \mathrm{~s}$ ), to see if the system is able to remain stable under strong disturbances. Finally, Figure $11 \mathrm{c}, \mathrm{f}, \mathrm{i}, \mathrm{l}$ show the quality of the voltages and currents and also confirm that there is a proper current tracking with respect to the grid voltage. 


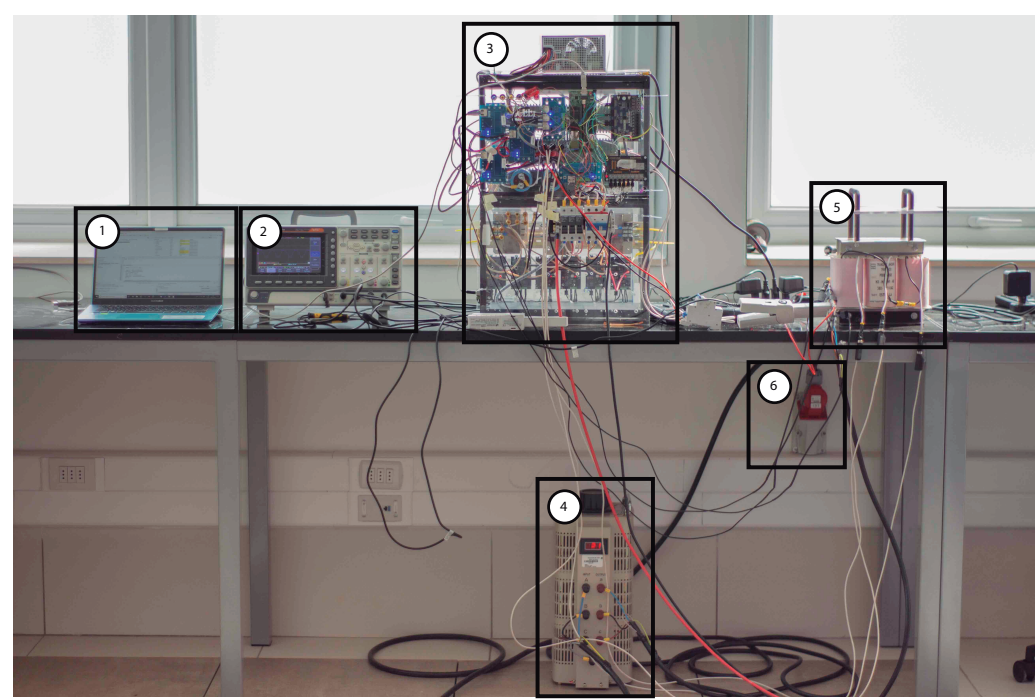

Figure 10. Experimental setup: (1) programming computer, (2) oscilloscope for signal acquisition, (3) converter, measurement boards, microcontroller, $L$ filter, AC input and DC input, (4) autotransformer to decrease grid voltage, (5) isolation transformer and (6) three-phase grid.

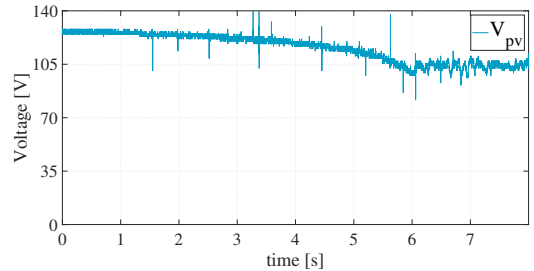

(a)

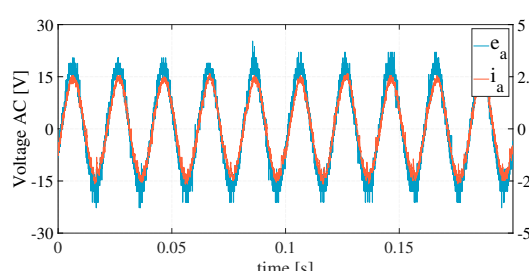

(c)

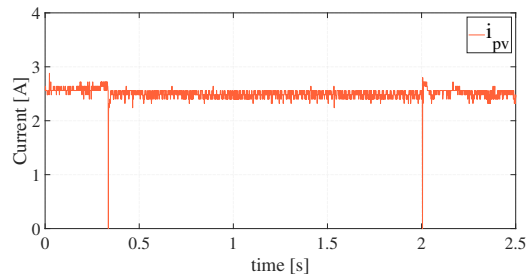

(e)

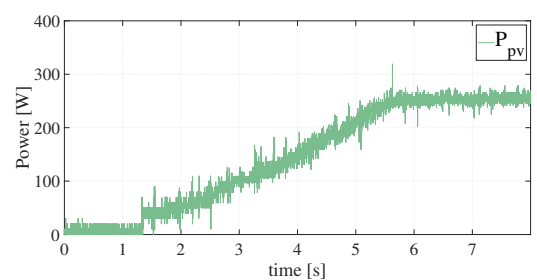

(g)

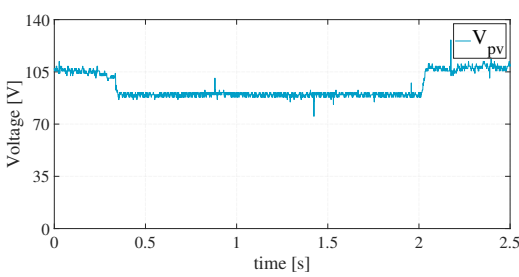

(b)

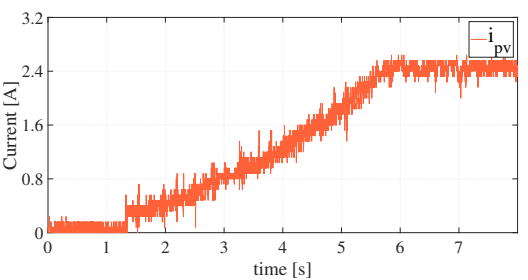

(d)

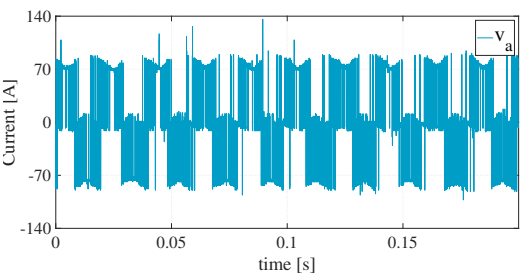

(f)

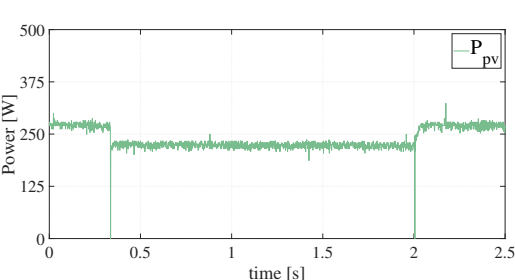

(h)

Figure 11. Cont. 


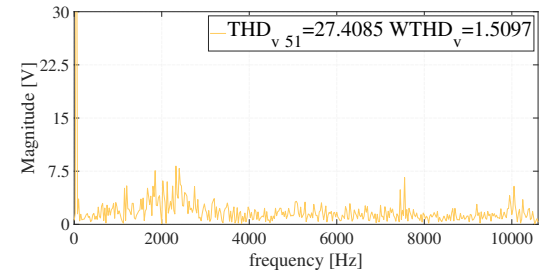

(i)

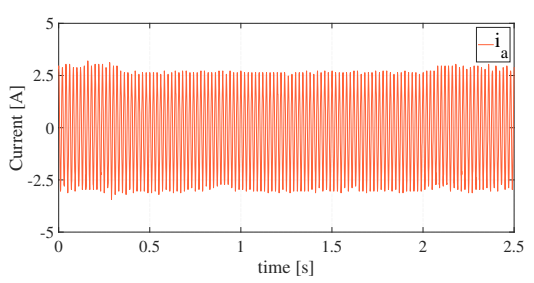

(k)

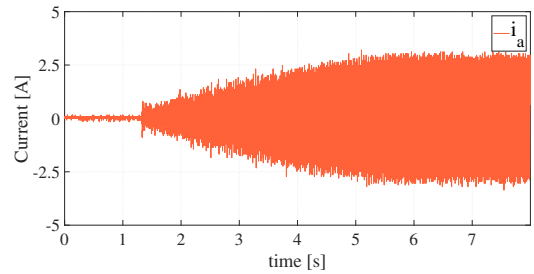

(j)

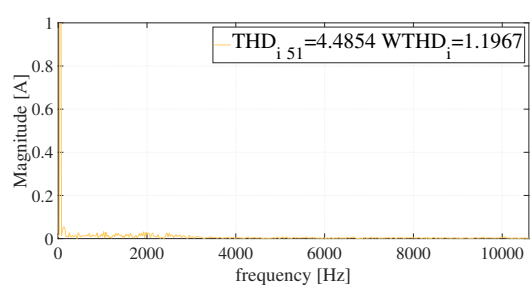

(1)

Figure 11. Experimental results: (a) DC link voltage during MPP's search, (b) DC link voltage during disconnection and subsequent connection of one of the solar panels, (c) current $i_{a}$ and steady state voltage $e_{a},(\mathbf{d})$ solar array current during MPP's search, (e) solar panel current during the disconnection and subsequent connection of one of the solar panels, (f) voltage $v_{a}$ in steady state, (g) solar array power during MPP's search, (h) solar array power during disconnection and subsequent connection of one of the solar panels, (i) spectral analysis of the voltage of (f) and calculation of THD and WTHD, (j) injected current $i_{a}$ during MPP's search, (k) injected current $i_{a}$ during the disconnection and subsequent connection of one of the solar panels, (l) spectral analysis of the current $i_{a}(\mathbf{c})$ and calculation of THD and WTHD.

\section{Discussion}

In both simulation and implementation, the control is capable of operating the system at the MPP, even during disturbances. The experimental response presents two main differences with respect to the simulation. Experimentally, the control in the MPPT requires a higher $\Delta T$ to be able to work properly. In experimental tests, the control works about 10 times slower compared to simulations, and it is possible that it may work faster, but this depends on the coupling place of the photovoltaic system, due to differences in electrical systems, since it is the inductance of the grid that defines how fast the variations in the current references can be made. In the experimental system the autotransformer and the isolation transformer add more inductance to the system. The other main difference is observed in the harmonic distortion of the signals. which is over twice the value of the simulations. This may be due to the signal adaptation stage, in which low-bandwidth operational amplifiers with a slow rate (LM324) are used, which causes the microcontroller to not read the correct signal. Nevertheless, both simulation and experimental results present the majority of its spectrum centered around 2200 [Hz] (44th harmonic), which makes the analysis of the distortion up to 51st harmonic present low values in the current signal, since higher order harmonics are attenuated in the signal due to the inductive nature of the system.

Comparing the proposed strategy against the traditional cascade control, the designed PI control has a better performance on the DC side, for it is able to reach the MPP in less time during the start and disturbances, and it also has less ripple in the voltage signals (Figure 6a) and current (Figure 6b). On the other hand, the predictive control strategies, despite having a higher mean absolute error during the disturbances (Figure 6e,g,i) in the current signals show a better behavior on the AC side, even in a highly distorted grid (Figure 9a), since they do not present harmonics at low frequency, this being quantifiable with the weighted total harmonic distortion (WTHD) index [44], which weights a lower value at higher harmonics compared to the THD index. 
By using current references in the MPPT strategy, it is possible to decrease the size of the capacitor in the DC link, since it is the inductive elements that determine the dynamics of the system. This compared to the PI strategy allows a decrease in system costs. It is even possible to observe from Figure 7c,f that lower-capacitance results in a lower THD index and a very similar WTHD between both situations.

When obtaining the current reference for the MPPT algorithm, the time it takes for the system to reach the MPP is directly dictated by the value of $\Delta i$, being an advantage over the traditional cascade strategy, since the control PI has a dynamics set by the $\Delta v$ of the MPPT voltage plus the dynamics of the controller. The PI control does not ensure good performance for different plants due to its linear nature.

\section{Conclusions}

In this work, a combination of predictive current control and a current-based maximum power point-tracking strategy is proposed, in which disturbances are performed on the AC side and the behavior of the DC side is analyzed.

Simulation results compare the proposed scheme for different capacitive values against the controlled system by cascade loops using PI-type controllers. Then, the experimental results of the proposed algorithm are presented, considering disturbances in the available power.

In light of the results, it is possible to say that despite external (environmental) disturbances, the photovoltaic solar system remains operating at its maximum power point. The system is capable of operating when disturbances occur in environmental conditions and uncertain system's electric parameters. The application of the proposed algorithm implies less dependency on the capacitive parameters; thus, dynamics of the system are determined by inductive elements, enabling the use of less voluminous and lower cost capacitors.

When comparing the classic cascade control and the proposed control, it is found that the DC-side signals have an improved behavior considering PI-type controls. The presented control strategy shows higher quality in the injected current into the electrical system, making possible the connection of solar arrays at different points, without causing problems to the control algorithm and consequently, to the quality of power supply. Generally speaking, it can be observed that the proposed algorithm is able to provide better quality currents to the system, there is a better follow up of the references and the majority of the harmonic content is found at a high frequency

Further work must contemplate the study of the strategy exploring algorithms that allow the consideration of virtual inertia, thus, allowing the photovoltaic plants to present changes in power variation that contribute to the stability of the electrical grid in case of failure.

Author Contributions: Conceptualization, C.M.; methodology, C.M. and M.R.; software, C.M.; validation, C.M. and A.V.; formal analysis, M.R., C.R.B., J.M. and R.R.; investigation, C.M.; resources, M.R.; writing —original draft preparation, C.M. and A.V.; writing—review and editing, C.M., M.R. and A.V.; visualization, C.M.; supervision, M.R. and C.R.B.; project administration, M.R.; funding acquisition, M.R. and P.W. All authors have read and agreed to the published version of the manuscript.

Funding: This research was funded by FONDECYT/regular/2016-1160690.

Acknowledgments: This work was supported by the Chilean Government under ANID-PFCHA/MagísterNacional/2018-22180174 Scholarship, ANID/FONDECYT/1191028 Project and by SERC Chile (CONICYT/FONDAP /15110019).

Conflicts of Interest: The authors declare no conflict of interest. 


\begin{tabular}{|c|c|}
\hline \multicolumn{2}{|c|}{ Abbreviations } \\
\hline \multicolumn{2}{|c|}{ The following abbreviations are used in th } \\
\hline \multirow{2}{*}{\multicolumn{2}{|c|}{ MPPT Maximum Power Point-Tracking }} \\
\hline & \\
\hline $\mathrm{MPC}$ & Model Predictive Control \\
\hline DC & Direct Current \\
\hline & Proportional Integrative \\
\hline & Alternating Current \\
\hline $\mathrm{P} \& \mathrm{O}$ & Perturbation and Observation \\
\hline \multirow{2}{*}{ MPP } & Maximum Power Point \\
\hline & Resistive Inductive \\
\hline
\end{tabular}

\section{References}

1. Kabir, E.; Kumar, P.; Kumar, S.; Adelodun, A.A.; Kim, K.H. Solar energy: Potential and future prospects. Renew. Sustain. Energy Rev. 2018, 82, 894-900. [CrossRef]

2. Sechilariu, M.; Molines, N.; Richard, G.; Martell-Flores, H.; Locment, F.; Baert, J. Electromobility framework study: Infrastructure and urban planning for EV charging station empowered by PV-based microgrid. IET Electr. Syst. Transp. 2019, 9, 176-185. [CrossRef]

3. Sivaram, V. Taming the Sun: Innovations to Harness Solar Energy and Power the Planet, 1st ed.; MIT Press: Cambridge, MA, USA, 2018; p. 371.

4. Mohandes, B.; El Moursi, M.S.; Hatziargyriou, N.; El Khatib, S. A review of power system flexibility with high penetration of renewables. IEEE Trans. Power Syst. 2019, 34, 3140-3155. [CrossRef]

5. Grainger, J.J.; Stevenson, W.D. Análisis de Sistemas de Potencia; McGraw-Hill: Mexico City, Mexico, 1996; p. 740.

6. Peng, Q.; Jiang, Q.; Yang, Y.; Liu, T.; Wang, H.; Blaabjerg, F. On the Stability of Power Electronics-Dominated Systems: Challenges and Potential Solutions. IEEE Trans. Ind. Appl. 2019, 55, 7657-7670. [CrossRef]

7. Hosseini, S.M.; Carli, R.; Dotoli, M. Robust optimal energy management of a residential microgrid under uncertainties on demand and renewable power generation. IEEE Trans. Autom. Sci. Eng. 2020. [CrossRef]

8. Bellinaso, L.V.; Figueira, H.H.; Basquera, M.F.; Vieira, R.P.; Gründling, H.A.; Michels, L. Cascade Control with Adaptive Voltage Controller Applied to Photovoltaic Boost Converters. IEEE Trans. Ind. Appl. 2018, 55, 1903-1912. [CrossRef]

9. Melo, F.C.; Garcia, L.S.; De Freitas, L.C.; Coelho, E.A.; Farias, V.J.; De Freitas, L.C. Proposal of a Photovoltaic AC-Module with a Single-Stage Transformerless Grid-Connected Boost Microinverter. IEEE Trans. Ind. Electron. 2018, 65, 2289-2301. [CrossRef]

10. Errouissi, R.; Al-Durra, A. Disturbance Observer-Based Control for Dual-Stage Grid-Tied Photovoltaic System under Unbalanced Grid Voltages. IEEE Trans. Ind. Electron. 2018, 66, 8925-8936. [CrossRef]

11. Abu-Zaher, M.; Atia, Y.; Abo-Elyousr, F.K.; El-Zohri, E. Experimental Realization for P\&O Maximum Power Point Tracking Applied for Single-Stage Three-Phase Grid-Connected Photovoltaic System. In Proceedings of the 2019 21st IEEE International Middle East Power Systems Conference (MEPCON), Cairo, Egypt, 17-19 December 2019; pp. 704-709.

12. Kadri, R.; Gaubert, J.P.; Champenois, G. An Improved maximum power point tracking for photovoltaic grid-connected inverter based on voltage-oriented control. IEEE Trans. Ind. Electron. 2011, 58, 66-75. [CrossRef]

13. Kovacs, L.; Fodor, D. New Flatness Measurement Method of Aluminum Electrolytic Capacitor Can for heat stabilization to PWM Converter. In Proceedings of the 2018 IEEE International Symposium on Power Electronics, Electrical Drives, Automation and Motion (SPEEDAM), Amalfi, Italy, 20-22 June 2018; pp. 533-538.

14. Ferdous, M.J.; Salma, U.; Kabir, S.; Sharif, S.E. Mitigating the Voltage Fluctuation of DC Capacitor and Coupling Point Using Capacitor Current Control Method in DFIG System. In Proceedings of the 2018 IEEE International Conference on Innovation in Engineering and Technology (ICIET), Dhaka, Bangladesh, 27-28 December 2018; pp. 1-6.

15. Ferencz, I.; Petreuş, D. Current Mode Control of a Solar Inverter with MPPT Algorithm. In Proceedings of the 2019 42nd IEEE International Spring Seminar on Electronics Technology (ISSE), Wroclaw, Poland, 15-19 May 2019; pp. 1-7.

16. Gong, C.; Hu, Y.; Ma, M.; Yan, L.; Liu, J.; Wen, H. Accurate FCS Model Predictive Current Control Technique for Surface-Mounted PMSMs at Low Control Frequency. IEEE Trans. Power Electron. 2019, 35, 5567-5572. [CrossRef]

17. Shi, X.; Zhu, J.; Li, L.; Lu, D.D.C. Low-Complexity Dual-Vector-Based Predictive Control of Three-Phase PWM Rectifiers without Duty-Cycle Optimization. IEEE Access 2020, 8, 77049-77059. [CrossRef]

18. Trivedi, M.S.; Keshri, R.K. Evaluation of Predictive Current Control Techniques for PM BLDC Motor in Stationary Plane. IEEE Access 2020, 8, 46217-46228. [CrossRef]

19. Paredes, M.; Ruiz, D.; Jara, W.; Pena, R.; Riedemann, J. Model Predictive Control of a Quasi-Three-Level Inverter Topology Supplying Multiple Solar-Powered Pumps. In Proceedings of the 2020 IEEE 11th International Symposium on Power Electronics for Distributed Generation Systems (PEDG), Dubrovnik, Croatia, 8-11 June 2020; pp. 225-229.

20. Kashif, M.; Murshid, S.; Singh, B. Continuous Control Set Model Predictive Controller for PMSM Driven Solar PV Water Pumping System. In Proceedings of the 2019 IEEE International Conference on Environment and Electrical Engineering and 2019 IEEE Industrial and Commercial Power Systems Europe (EEEIC/I\&CPS Europe), Genova, Italy, 11-14 June 2019; pp. 1-6. 
21. Satti, M.B.; Hasan, A. Direct model predictive control of novel h-bridge multilevel inverter based grid-connected photovoltaic system. IEEE Access 2019, 7, 62750-62758. [CrossRef]

22. Zhang, Z.; Li, Z.; Kazmierkowski, M.P.; Rodriguez, J.; Kennel, R. Robust predictive control of three-level NPC back-to-back power converter PMSG wind turbine systems with revised predictions. IEEE Trans. Power Electron. 2018, 33, 9588-9598. [CrossRef]

23. Jun, E.S.; Nguyen, M.H.; Kwak, S.S. Model Predictive Control Method with NP Voltage Balance by Offset Voltage Injection for Three-Phase Three-Level NPC Inverter. IEEE Access 2020, 8, 172175-172195. [CrossRef]

24. Dangor, M.R.E.; Aswat, M.; Cronje, W. Flyback Converter Controlled by Model-Based Current MPPT for a Photovoltaic Power System. In Proceedings of the 2019 IEEE Southern African Universities Power Engineering Conference/Robotics and Mechatronics/Pattern Recognition Association of South Africa (SAUPEC/RobMech/PRASA), Bloemfontein, South Africa, 28-30 January 2019; pp. 481-486.

25. Xia, Y.; Yu, M.; Wang, X.; Wei, W. Describing function method based power oscillation analysis of LCL-filtered single-stage PV generators connected to weak grid. IEEE Trans. Power Electron. 2018, 34, 8724-8738. [CrossRef]

26. Lee, J.; Jo, J.; Cha, H. MPPT Performance Comparison Between Duty-Cycle Control and Current Control for Photovoltaic Power Conditioning System. In Proceedings of the 2018 IEEE 21st International Conference on Electrical Machines and Systems (ICEMS), Jeju, Korea, 7-10 October 2018; pp. 1036-1040.

27. Wu, B.; Keyue, S. A current control MPPT method in high power solar energy conversion system. In Proceedings of the 2014 IEEE Applied Power Electronics Conference and Exposition-APEC 2014, Fort Worth, TX, USA, 16-20 March 2014; pp. 3021-3025.

28. Singh, A.K.; Kumar, S.; Singh, B. Solar PV Energy Generation System Interfaced to Three Phase Grid with Improved Power Quality. IEEE Trans. Ind. Electron. 2019, 67, 3798-3808. [CrossRef]

29. Sebaaly, F.; Vahedi, H.; Kanaan, H.Y.; Al-Haddad, K. Novel current controller based on MPC with fixed switching frequency operation for a grid-tied inverter. IEEE Trans. Ind. Electron. 2017, 65, 6198-6205. [CrossRef]

30. Ibrahim, I.A.; Hossain, J.; Duck, B.C.; Fell, C.J. An Adaptive Wind Driven Optimization Algorithm for Extracting the Parameters of a Single-Diode PV Cell Model. IEEE Trans. Sustain. Energy 2019, 11, 1054-1066. [CrossRef]

31. Yang, Z.; Sun, J.; Zha, X.; Tang, Y. Power decoupling control for capacitance reduction in cascaded-H-bridge-converter-based regenerative motor drive systems. IEEE Trans. Power Electron. 2018, 34, 538-549. [CrossRef]

32. Alluhaybi, K.; Batarseh, I.; Hu, H. Comprehensive review and comparison of single-phase grid-tied photovoltaic microinverters. IEEE J. Emerg. Sel. Top. Power Electron. 2019, 8, 1310-1329. [CrossRef]

33. Karafil, A.; Ozbay, H.; Oncu, S. Design and Analysis of Single Phase Grid Tied Inverter with PDM MPPT Controlled Converter. IEEE Trans. Power Electron. 2019, 35, 4756-4766. [CrossRef]

34. Mirzaeva, G.; Goodwin, G.C.; McGrath, B.P.; Teixeira, C.; Rivera, M.E. A generalized MPC framework for the design and comparison of VSI current controllers. IEEE Trans. Ind. Electron. 2016, 63, 5816-5826. [CrossRef]

35. Liu, B.; Zhuo, F.; Zhu, Y.; Yi, H.; Wang, F. A three-phase PLL algorithm based on signal reforming under distorted grid conditions. IEEE Trans. Power Electron. 2014, 30, 5272-5283. [CrossRef]

36. Bahrami, A.; Norambuena, M.; Narimani, M.; Rodriguez, J. Model Predictive Current Control of a Seven-Level Inverter with Reduced Computational Burden. IEEE Trans. Power Electron. 2019, 35, 5729-5740. [CrossRef]

37. Rodriguez, J.; Cortes, P. Predictive Control of Power Converters and Electrical Drives; John Wiley \& Sons: Hoboken, NJ, USA, 2012; Volume 40.

38. Vazquez, S.; Rodriguez, J.; Rivera, M.; Franquelo, L.G.; Norambuena, M. Model Predictive Control for Power Converters and Drives: Advances and Trends. IEEE Trans. Ind. Electron. 2017, 64, 935-947. [CrossRef]

39. Mora, A.; Cárdenas-Dobson, R.; Aguilera, R.P.; Angulo, A.; Donoso, F.; Rodriguez, J. Computationally Efficient Cascaded Optimal Switching Sequence MPC for Grid-Connected Three-Level NPC Converters. IEEE Trans. Power Electron. 2019, 34, 12464-12475. [CrossRef]

40. Karamanakos, P.; Geyer, T. Guidelines for the design of finite control set model predictive controllers. IEEE Trans. Power Electron. 2019, 35, 7434-7450. [CrossRef]

41. Cortes, P.; Rodriguez, J.; Silva, C.; Flores, A. Delay compensation in model predictive current control of a three-phase inverter. IEEE Trans. Ind. Electron. 2011, 59, 1323-1325. [CrossRef]

42. Villarroel, F.; Espinoza, J.; Perez, M.A.; Ramirez, R.; Baier, C.; Sbarbaro, D.; Silva, J.; Reyes, M. Stable shortest horizon FCS-MPC output voltage control in non-minimum phase boost-type converters based on input-state linearization. IEEE Trans. Energy Convers. 2021. [CrossRef]

43. Bevrani, H.; Franï, B.; Ise, T. Microgrid Dynamics and Control; John Wiley \& Sons: Hoboken, NJ, USA, 2017.

44. Santos, W.R.N.; da Silva, E.R.C.; Jacobina, C.B.; de Moura Fernandes, E.; Oliveira, A.C.; Matias, R.R.; Guedes Filho, D.F.; Almeida, O.M.; Santos, P.M. The transformerless single-phase universal active power filter for harmonic and reactive power compensation. IEEE Trans. Power Electron. 2013, 29, 3563-3572. [CrossRef] 